\title{
Intraocular involvement with subretinal pigment epithelium infiltrates by mycosis fungoides
}

\author{
Barbara C Erny, Peter R Egbert, Irene M Peat, K Shorrock, A Ralph Rosenthal
}

\begin{abstract}
We report a case of intraocular mycosis fungoides in a 48-year-old man. The patient presented with decreased visual acuity, white subretinal lesions, and vitritis. Post-mortem histopathology revealed malignant $T$ cell infiltrates consistent with mycosis fungoides in the retina, vitreous, and between the retinal pigment epithelium (RPE) and Bruch's membrane. Focal atrophy of the RPE, along with the sub-RPE infiltrates, correlated with the clinically visible fundus lesions.
\end{abstract}

Mycosis fungoides is a cutaneous $\mathrm{T}$ cell lymphoma, which can progress to generalised disease. ${ }^{1}$ It commonly presents with a long phase of 'premycotic' skin lesions. These progress to patches on the skin, which may or may not become plaques, and eventually tumours. ${ }^{2}$ The clinical course of skin involvement varies from chronic to rapidly progressive, and is unpredictable. ${ }^{3}$ Systemic involvement is late in the course of the disease, and usually involves the lymph nodes, liver, spleen, and/or central nervous system. ${ }^{4}$ Because the majority of patients develop the disease between the ages of 40 and 60 , many of them die of unrelated causes before the disease becomes widespread.

Eyelid and conjunctival involvement is not unusual in the course of mycosis fungoides. ${ }^{5}$ Other external ocular involvement has been reported, including cornea, ${ }^{6}$ caruncle, ${ }^{7}$ sclera, ${ }^{6}$ and orbit. ${ }^{8}$ Intraocular lesions are rare, and only a few individual cases have been reported. Only one of the previous reports records both the clinical and pathological appearance of intraocular mycosis fungoides. ${ }^{9}$

We present here a patient followed up closely for an ocular disease that resembled fungal endophthalmitis but was histologically proved to be mycosis fungoides.

Stanford University

Department of

Ophthalmology,

Stanford, California,

USA

B C Erny

P R Egbert

Leicester Royal

Infirmary, Leicester,

England

I M Peat

K Shorrock

A R Rosenthal

Correspondence to

Barbara C Erny, MD, Stanford University Department of Ophthalmology, Room A-157, Stanford University Medical Center, Stanford, Californi 94305, USA.

Accepted for publication 4 April 1991 of blurring of vision mainly in the left eye. Ophthalmic examination revealed bilateral disc swelling and small white lesions in the fundus (Figs 1A, B. The disc swelling resolved spontaneously. Four weeks later his vision dropped to $6 / 12$ in the right eye and counting fingers in the left. The left eye showed anterior uveitis, and severe vitritis with active retinitis in the posterior pole (Fig 2). The left eye had also developed a conjunctival perilimbal nodular yellow infiltrate (Fig 3). A presumed diagnosis of candida chorioretinitis was made, and the patient was treated with intravitreal amphotericin and oral ketoconazole. Cultures and stains of vitreous biopsies were negative, and oral ketocanazole was continued. By 5 December the right eye also developed a small white lesion in the macula (Fig 4), a limbal lesion, and conjunctival infiltrates.

At the same time the patient was admitted to hospital for control of pain and a newly discovered left sided abdominal mass. He died on 21 December 1989, with a diagnosis of mycosis fungoides and widespread lymphoma.

\section{POST MORTEM FINDINGS}

The body was covered with numerous crusting skin lesions up to $2 \mathrm{~cm}$ in diameter. There was evidence of extensive involvement of the lymph nodes by lymphoma, which also appeared to be infiltrating retroperitoneal tissues.
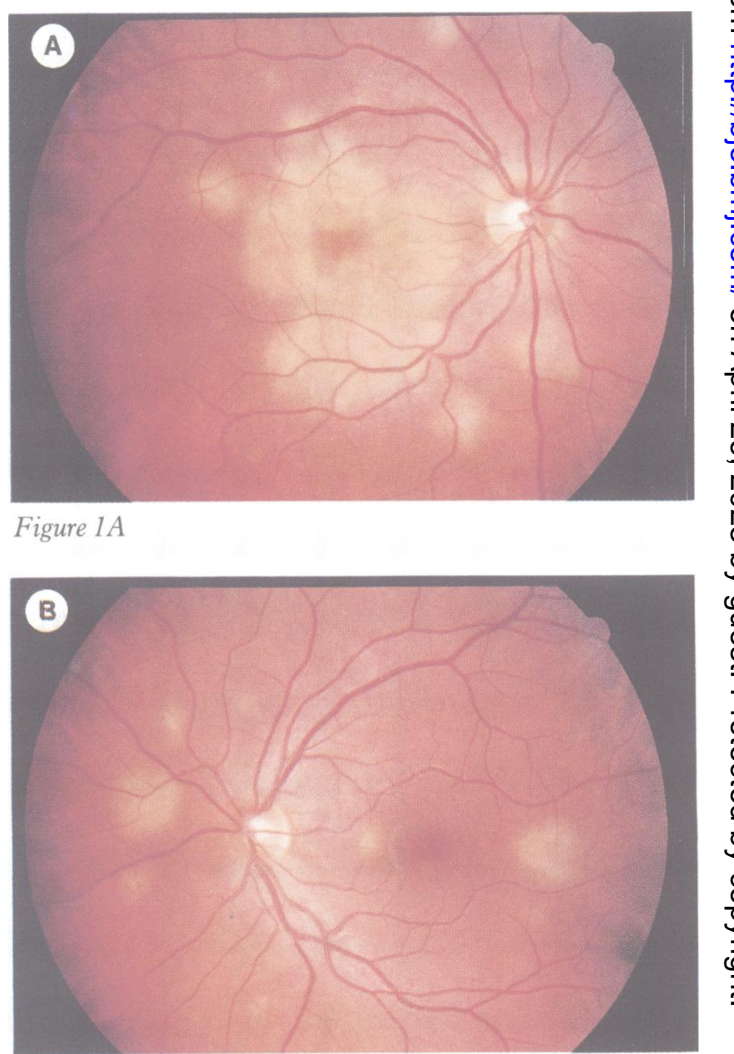

Figure 1B

Figure 1 Fundus, left eye. A Small circumscribed white subretinal lesions were seen throughout the mid periphery of the retina. $B$ There was one lesion in the macula. 


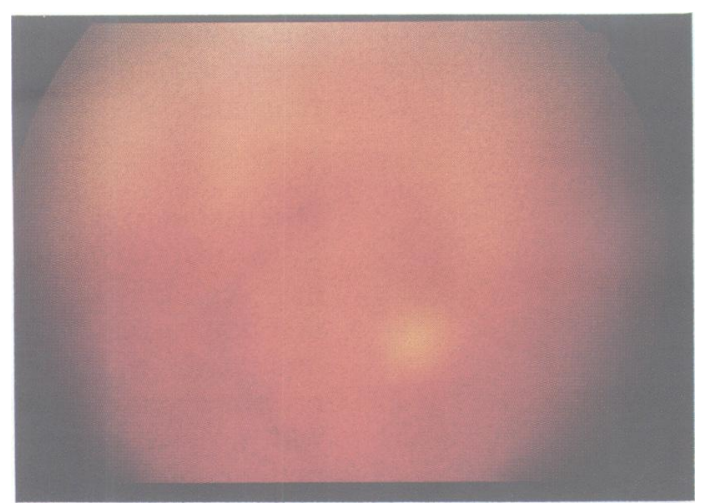

Figure 2 Fundus, left eye. Four weeks after the retinal lesions were first observed the patient developed vitritis with active retinitis.

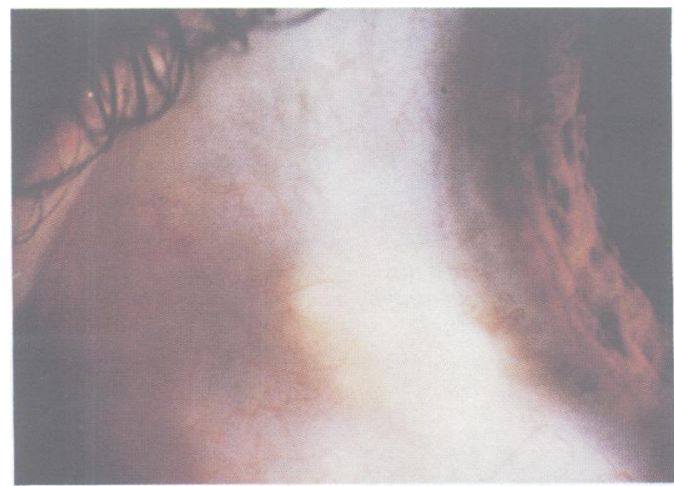

Figure 3 Left eye. This nodular perilimbal conjunctival infiltrate was noted four weeks after the patient's initial eye examination.

Microscopically the dermis displayed a diffuse infiltrate of small lymphocytes plus occasional larger cells with bizarre hyperchromatic nuclei. In some areas there was infiltration into the epidermis, though discrete microabcesses were not identified. There was heavy lymphoid infiltrates within the cortex of the left kidney which extended to the surface and infiltrated perinephric tissues. A similar lymphoid infiltrate was seen in the myocardium and testis. Lymph nodes from the periaortic region also showed efface-

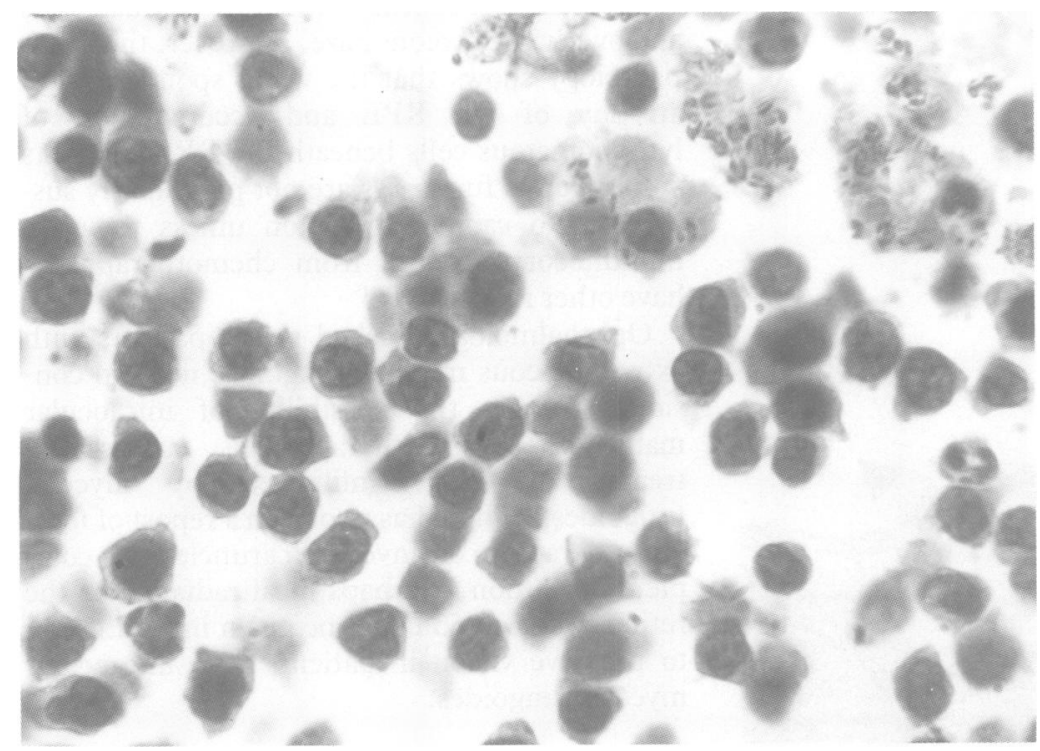

Figure 5 Lymphomatous infiltrate beneath the RPE contains cells with scanty cytoplasm and large pleomorphic nuclei with convoluted borders, consistent with mycosis fungoides.

(Haematoxylin and eosin, $\times 400$.)

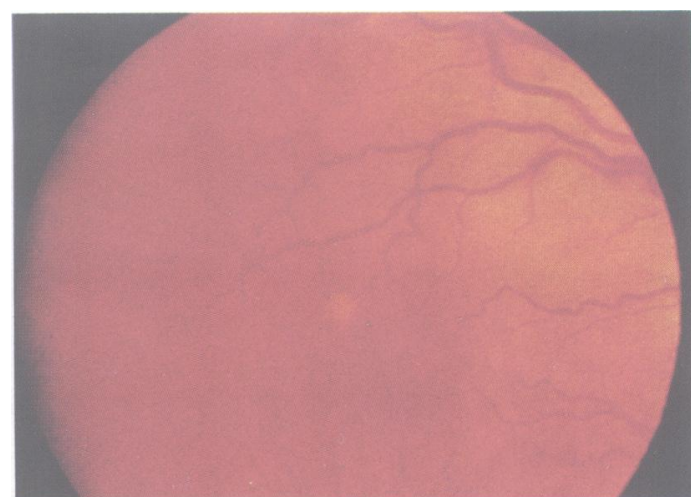

Figure 4 Fundus, right eye. Small white subretinal lesion in the macula.

ment of the architecture by a similar infiltrate, which extended widely into the surrounding fatty tissue. Immunocytochemical markers indicated that the infiltrate was predominantly composed of $\mathrm{T}$ lymphocytes.

The histological appearances were consistent with a $\mathrm{T}$ cell lymphoma arising in mycosis fungoides and leading to diffuse visceral infiltration.

\section{OCULAR HISTOPATHOLOGY}

Both eyes showed similar findings, these being more pronounced in the left eye. Anteriorly the eyes were normal. The striking feature in the posterior segment was the presence of abnormal lymphocytes, which were consistent with mycosis fungoides, between Bruch's membrane and the retinal pigment epithelium (RPE). The cells had scanty cytoplasm and large pleomorphic nuclei with convoluted borders (Fig 5). The infiltrate formed a diffuse layer, 1 to 15 cells thick, under the equatorial and peripheral RPE, and also extended a short distance under the pars plana epithelium. The thickness of this infiltrate varied throughout the specimen and often changed abruptly from sparse to dense. The overlying RPE showed variable focal degeneration and atrophy (Fig 6). The retina contained loose focal infiltrates of lymphomatous cells in the nerve fibre layer and ganglion cell layer, particularly round the retinal vessels (Fig 7). The outer retinal layers were normal. The choroid had a mild diffuse infiltrate of similar abnormal lymphocytes (Fig 8). Lymphomatous cells also infiltrated the small amount of vitreous base which remained after the vitrectomy (Fig 9). The ciliary body, iris, and episclera contained a slight lymphocytic infiltrate but no large lymphomalike cells.

The optic nerve and conjunctiva were not available for examination.

\section{IMMUNOHISTOPATHOLOGY}

The isolated cell population found between the RPE and Bruch's membrane was studied further by immunoperoxidase stains on paraffin sections. There was a positive reaction for the leucocyte common antigen (PD7) and two pan-T cell markers (L60, A6). The pan-B marker (L26) was non-reactive, which would be unusual in a benign lymphoid infiltrate. Therefore the find- 


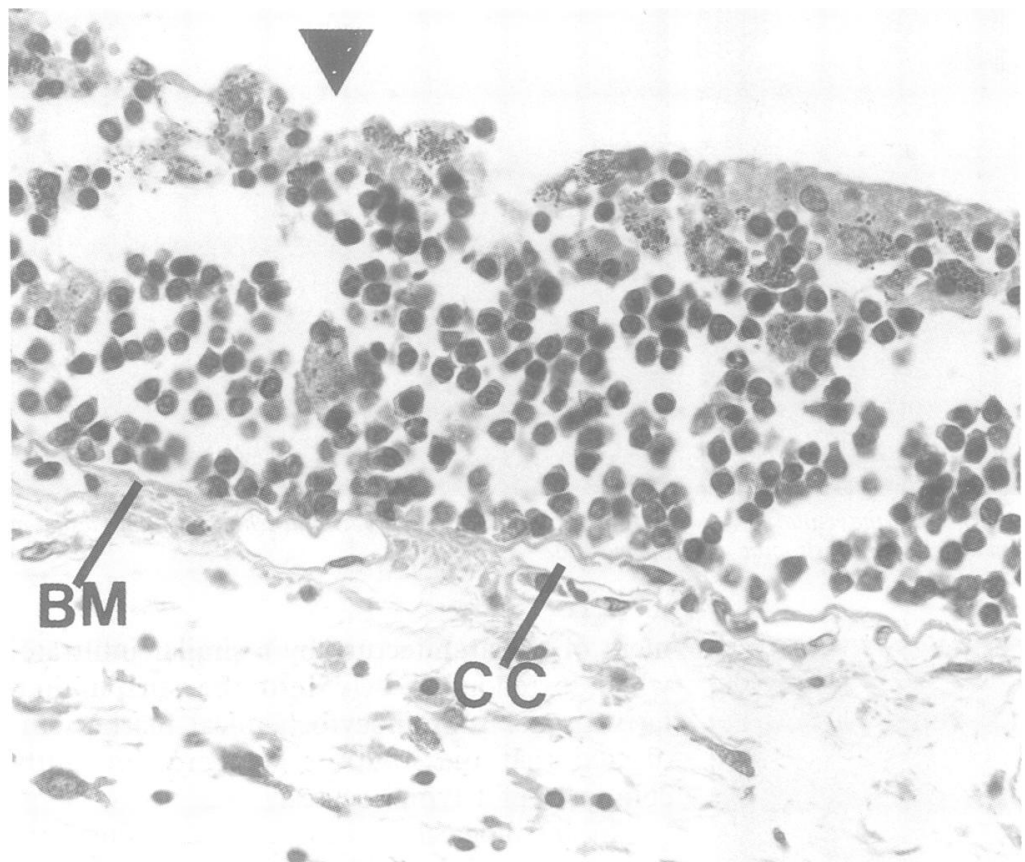

Figure 6 The infiltrate forms a diffuse layer of lymphomatous cells under the RPE. In this area the infiltrate is thick. The overlying RPE exhibits variable focal degeneration and atrophy (arrowhead). Bruch's membrane (BM) is intact, and the choriocapillaris $(C C)$ is normal. (Haematoxylin and eosin, $\times 200$.)

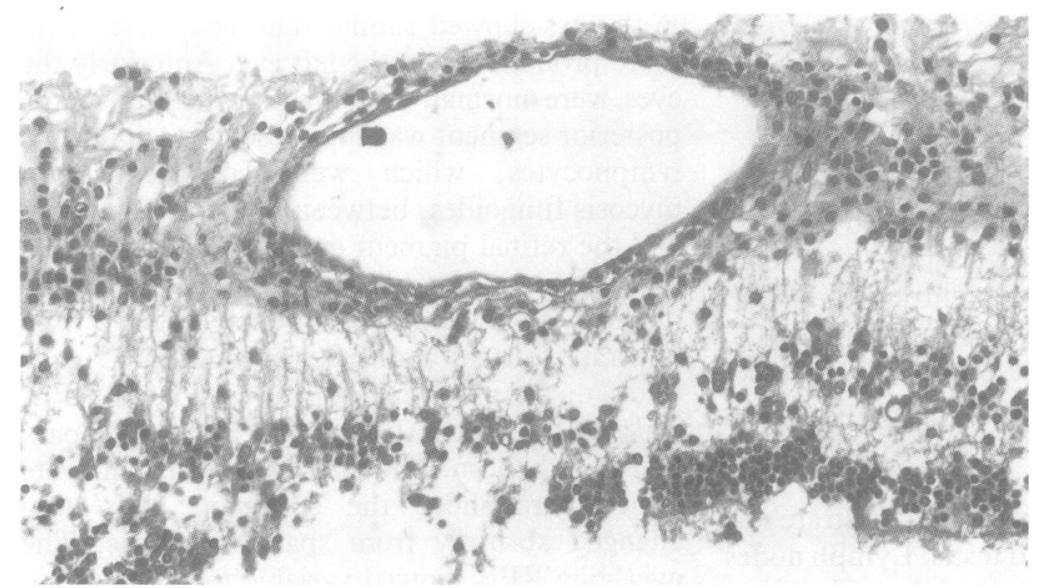

Figure 7 The retina contains loose focal infiltrates of lymphomatous cells in the nerve fibre layer and ganglion cell layer, here shown concentrated around a retinal vessel. (Haematoxylin and eosin, $\times 200$.)

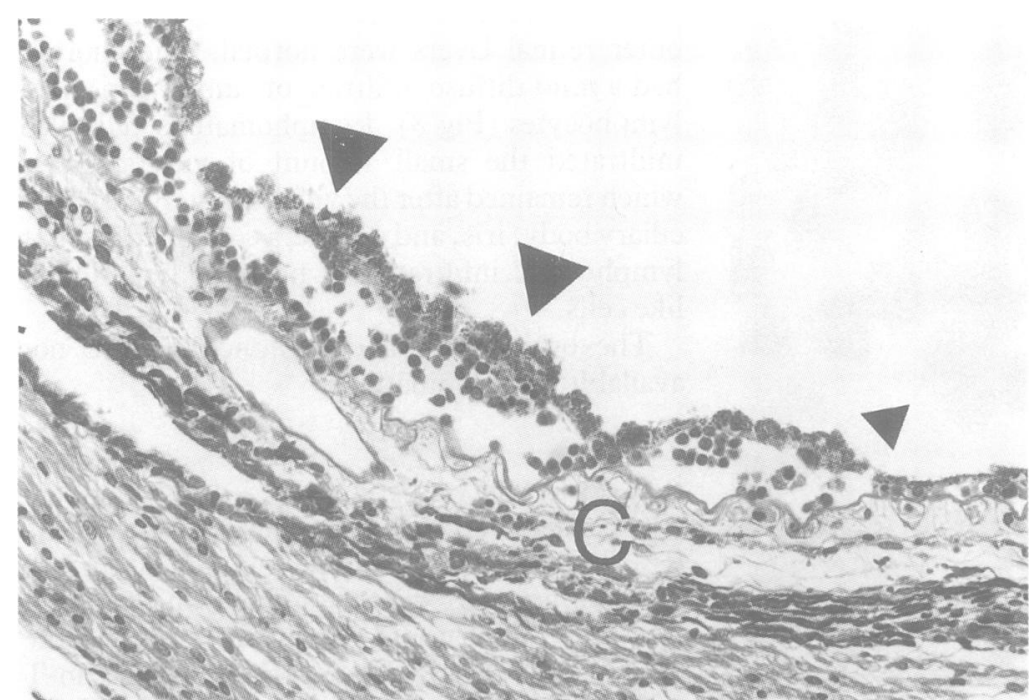

Figure 8 In this area there is a thin infiltrate of lymphomatous cells beneath the RPE (large arrowheads) and beneath the epithelium of the pars plana (small arrowhead). The choroid $(C)$ contains a scanty lymphomatous infiltrate. (Haematoxylin and eosin, $\times=100$.) ings indicated exclusive $\mathrm{T}$ cell proliferation consistent with involvement of the eye by micosis fungoides.

\section{Discussion}

Intraocular involvement of mycosis fungoides has been rarely reported. Gartner ${ }^{10}$ reported the first known case, in which the choroid was infiltrated with neoplastic cells. Hogan" presented a case in which the uvea was infiltrated with neoplastic cells and the optic nerve had tumour anterior to the lamina, which extended to the adjacent retina. Keltner $e t a l^{9}$ described a patient with involvement of the central nervous system and eyes in whom at necropsy mycosis fungoides cells were found in the retina, optic disc, and vitreous. Foerster ${ }^{12}$ presented a case and described the pathological finding of neoplastic cells forming a diffuse layer beneath the $\mathrm{RPE}$, as seen in the present case. Intraocular involvement has been noted only in the end stage of the disease in all of these cases: from 17 days ${ }^{11}$ to one year before death. ${ }^{12}$ In our patient the eye involvement was discovered seven weeks before his death.

In this paper we present a case of mycosis fungoides with clinical and pathological correlates of the intraocular involvement, which most strikingly includes infiltrates between the RPE and Bruch's membrane. In our sections it appears that cells have arrived in the sub-RPE potential space by crossing Bruch's membrane from the choroid. Barr $e t a l^{13}$ reported two cases of similar lesions in large cell lymphoma. This finding suggests that lymphocytes from various lymphomas may have a predilection to accumulate in the sub-RPE space. The retinal perivascular infiltrates and vitreous metastases are similar to those reported by Keltner et $a l^{9}$ Metastases to the retina characterised pathologically by collarettes of tumour cells surrounding retinal vessels, evidently occur by haematogenous spread, as has also been reported in leukaemia. ${ }^{14}$

The lesions in our patient clinically mimicked candida chorioretinitis, with white retinal spots and overlying vitreous haze. However, the histopathology shows that the white spots are focal atrophy of the RPE and accumulation of lymphomatous cells beneath the RPE. Patients with mycosis fungoides are not particularly susceptible to candida infection unless they are immunocompromised from chemotherapy, or have other risk factors. ${ }^{15}$

Ophthalmologists asked to see patients with extracutaneous mycosis fungoides need to consider strongly the possibility of intraocular malignancy. Radiotherapy has successfully treated an orbit infiltrated by mycosis fungoides. ${ }^{16}$ There has also been a report of focal radiotherapy to an involved caruncle with complete resolution. ${ }^{7}$ Perhaps focal radiation to the retina and choroid could be given in an attempt to preserve vision in patients with intraocular mycosis fungoides. 


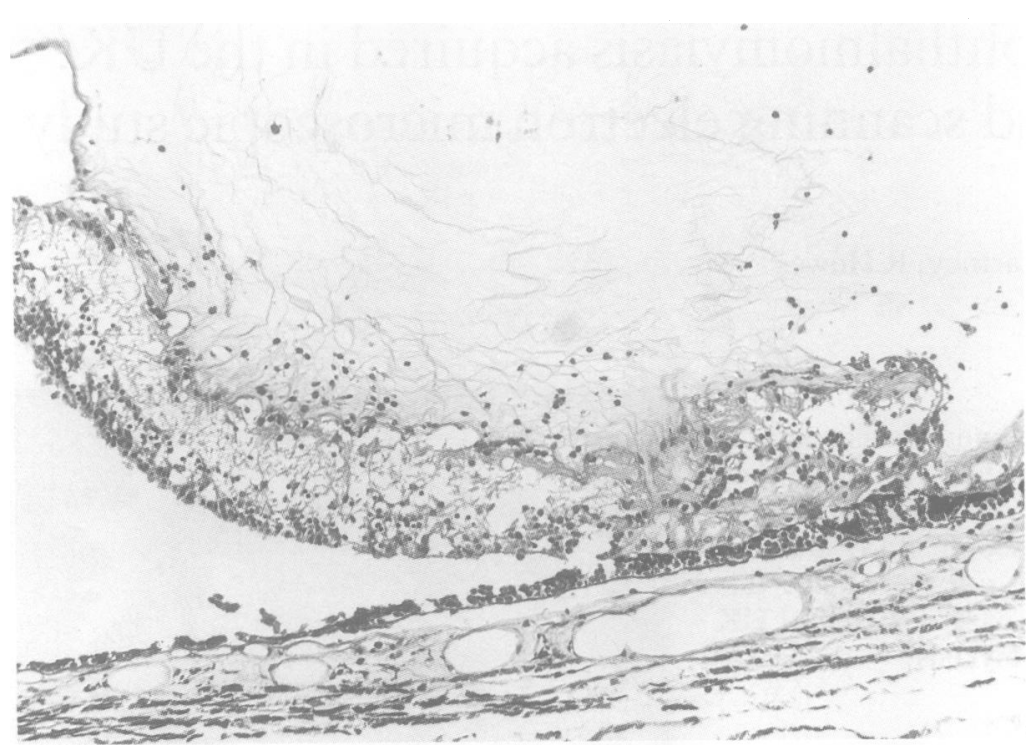

Figure 9 Lymphomatous cells are seen infiltrating the remaining vitreous at the vitreous base adjacent to the ora serrata. (Haematoxylin and eosin, $\times 40$.)
1 Lutzner MA, Edelson RL, Schein P, et al. Cutaneous T-cell lymphomas: Sézary syndrome, mycosis fungoides and lymphomas: Sézary syndrome, mycosis fungoid

2 Hoppe RT, Wood GS, Abel EA. Mycosis fungoides and the Sézary syndrome: pathology, staging, and treatment. Curr Sézary syndrome: pathology, stag

3 Long JC, Mihm M. Mycosis fungoides with extracutaneous dissemination: a distinct clinicopathologic entity. Cancer 1974; 34: 1745-55.

4 Rappaport H, Thomas LB. Mycosis fungoides: the pathology of extracutanous involvement. Cancer 1974; 34: 1198-229.

5 Stenson S, Ramsay DL. Ocular findings in mycosis fungoides. Arch Ophthalmol 1981; 99: 272-7.

6 Wolter JR, Leenhouts TM, Hendrix RC. Corneal involvemen in mycosis fungoides. Am f Ophthalmol 1963; 55: 317-22.

7 Fradkin AH, Ruiz RS, Sloane JA. Mycosis fungoides involving the caruncle. Am $\mathcal{F}$ Ophthalmol 1969; 68: 719-22.

8 Brewitt H, Hartung J, Hoffman K. Lid und Orbitabeteiligung bei Mycosis fungoides. Klin Monatsbl Augenheilkd 1974; 164: $345-9$.

9 Keltner JL, Fritsch E, Cykiert RC, et al. Mycosis fungoides: intraocular and central nervous system involvement. Arch Ophthalmol 1977; 95: 645-50.

10 Gartner VJ. Mycosis fungoides mit Beteiligung der Aderhaut. Klin Montatsbl Augenheilkd 1957; 131: 61-9.

11 Hogan MJ. A case of intraocular mycosis fungoides. Read before Verhoeff Society meeting, Armed Forces Institute of Pathology, Washington DC, April 1972.

12 Foerster HC. Mycosis fungoides with intraocular involvement. Ophthalmology 1960; 64: 308-13.

13 Barr CC, Green WR, Payne JW, Knox DL, Jensen AD, Thompson RL. Intraocular reticulum cell sarcoma: Clinicopathologic study of four cases and review of the literature. pathologic study of four cases and
Surv Ophthalmol $1975 ; 19: 224-39$.

14 Green RW. Systemic diseases with retinal involvement. In: Spencer WH, ed. Ophthalmic pathology. Philadelphia: Saunders, 1985: 1057-64

15 Edwards JE Jr, Foos RY, Montgomerie JZ, Guze LB. Ocular manifestations of candida septicemia: review of seventy-six cases of hematogenous candida endophthalmitis. Medicine 1974; 53: 47-75.

16 Whitbeck E, Spiers ASD, Hussain M. Mycosis fungoides subcutaneous and visceral tumors, orbital involvement, and ophthalmoplegia. F Clin Oncol 1983; 1: 270-6. 